\title{
Effect of CFRP Strips Orientation on Performance of Strengthened Deep Beams
}

\author{
Ahmed Sagban Saadoon ${ }^{a *}$ \\ ${ }^{a}$ Department of Civil Engineering, College of Engineering, University of Basrah, Basrah, Iraq.
}

\author{
A R T ICLE INFO \\ Article history: \\ Received 24 August 2019 \\ Received in revised form 22 September 2019 \\ Accepted 24 September 2019
}

Keywords:

Deep beams

Strengthened beams

FRP strips

Shear span

\begin{abstract}
A B S T R A C T
This study was carried out in order to explore the behaviour of RC deep beams strengthening with CFRP strips. Eight simply supported deep beams were fabricated and tested under four-points loading scenario. Three different orientations for CFRP strips were used for strengthening the RC deep beams ; vertical, horizontal and inclined. All of the tested samples were of the same dimensions, concrete strength and steel reinforcement. A percentage increase in load carrying capacity of 48, 19 and 38\% (with respect to the unstrengthened beam) was gained for beams strengthened with vertical, horizontal and inclined FRP strips, respectively. It was concluded that the strengthening with FRP strips of vertical fabric orientation is more efficient than strengthening with horizontal or inclined orientation since the vertical orientation gives the highest load carrying capacity, largest deflections at ultimate load and smallest crack width. On the other hand, applied the FRP strips in a horizontal orientation was insufficient for the strengthening purposes.
\end{abstract}

() 2019 Hosting by University of Al-Qadisiyah. All rights reserved.

\section{Introduction}

Beams are classified into two classes: deep and shallow. This classified based upon the span/depth or shear span/depth ratio. According to the ACI code [1], deep beams are "members in which compression struts are developed between the loads and the supports, and has either clear span/overall depth $\leq 4$ or applied concentrated loads within twice the member depth from the face of support". These beams have been used in different engineering constructions. The behaviour of these beams differs from that of shallow behaviour class. In the case of shallow beams, linear strain distribution is developed, and the applied loads usually transfer through diagonal compression regions. The beam strength in such case is generally governed by flexure, and shear is supported by the uncracked concrete region, aggregate interlock, truss action of stirrups and dowel action of main bars. Whereas in deep beams, nonlinear strain distribution is developed, and the applied loads transfer similar to the strut and tie action, so the beam strength is generally governed by shear, and the hypotheses theory for shear does not work due to shear deformation and stress redistribution in cracked regions [2]. In severe environments, the classical steel reinforcement does not perform very well for the long term since its performance will change considerably due to the corrosion of steel which causes deterioration or cracking of the concrete structures. Many studies have been conducted to find the optimal solution to this problem. Different techniques have been proposed, such as galvanization, epoxy coating, cathodic protection and using stainless steel reinforcement, concrete additives, and fiber reinforced polymer (FRP) strengthening. Only the FRP strengthening gives a long term solution [3] due to superior properties of FRP composites such as corrosion resistant, higher stiffness and strength, lightweight, and easy handling and application. However, the cost and brittle behaviour of FRP composites are the main reasons behind the limited use of FRP composites [3]. Different studies have been dealt with the using of FRP composites as reinforcing, strengthening, wrapping, retrofitting and

\footnotetext{
* Corresponding author. Tel.: +964(0)7703277650.

E-mail address: ahmsag@gmail.com. (Ahmed Sagban Saadoon)
} 
repairing materials in deep beams. Islam et al. [4] studied the performance of six deficient deep beams strengthened externally by bonded FRP system. They pointed out that the FRP system causes a slower propagation of the diagonal cracks and increases the load carrying capacity of the beam . ALShraify [5] studied the performance of deep beams repaired and strengthened by FRP strips in shear situation. The results obtained showed that the percentages increase were (58 to $60 \%$ ) and ( 47 to $96 \%$ ) for the repaired and strengthened beams, respectively, with respect to the control beam. Lee [6] carried out an experimental study to explore the attitude of deep beams of T-section and with FRP sheets strengthening. It was noted that the fiber direction, strengthening length, and anchorage were the main parameters affecting the shear performance. Abbas and Abdulah [7] investigated the influence of different FRP strengthening cases on the capacity and behaviour of indirectly loaded flanged deep beams strengthened in shear. Chavan et al. [8] performed experimental tests on deep beams of an external FRP reinforcement to investigate its enhancement on the shear strength. A substantial increase in the strength was concluded and the main factor controlling the failure mode was the shear span/depth ratio. Alwash et al. [9] studied the behaviour of square concrete slabs reinforced by various ratios of CFRP reinforcement. It was found that the CFRP reinforced slab exhibited ultimate load capacity of $34.62 \%$ higher than steel reinforced slab. Makki et al. [10] worked on a nonlinear ANSYS analysis of RPC deep beams. Their results showed that the ANSYS analysis values were close to experimental values with a maximum difference not greater than $7.5 \%$ in the values of ultimate load.

The current work aims to explore the effect of FRP strips orientation on the load carrying capacity and behaviour of strengthened deep beams. This work consists of testing experimentally eight beams in which the whole distance between the two points load and the support for both sides is strengthened by FRP strips. The main variable is the orientation of FRP fibers.

\section{Experimental Work}

\subsection{Test Specimens}

The experimental work of this study involves fabricating and testing eight deep beams of simple supports condition. Six of these beams were externally strengthened with CFRP strips in shear while the two beams were taken as control samples. The flexural reinforcement and dimensions are similar for all of the tested beams. The dimensions of the beam were $1270 \mathrm{~mm}$ total long, $400 \mathrm{~mm}$ deep and $150 \mathrm{~mm}$ wide . It was reinforced longitudinally by three steel bars $(\varnothing 16 \mathrm{~mm})$ and transversely by vertical closed steel stirrups $(\varnothing 6 \mathrm{~mm}$ at $150 \mathrm{~mm}$ c/c spacing). No horizontal shear reinforcement was added to ensure that a shear failure will appear. A nominal concrete strength, around $60 \mathrm{MPa}$, was adopted for all of the tested beams. The distance between the point load and the support for both sides is strengthened by FRP strips. The FRP strips were applied to the surface of concrete in three orientations: vertical, horizontal and inclined by $45^{\circ}$ with horizontal axis, as shown in Fig. 1. For each beam's type, two identical specimens (denoted 1 and 2) having the same details were cast (in order to adopt the average results of them in discussion). Details of all beams are shown in Table 1.

\subsection{Materials}

The properties of the steel bars, FRP strips and epoxy used in this study are listed in Table 2. A concrete batch was used to cast every two identical beams. The specimens were cast using normal concrete mixes of proportion 1:1:2 and with water/cement ratio of 0.3 . The maximum size of coarse aggregate was $20 \mathrm{~mm}$ and a plasticizer admixture $(20 \mathrm{ml}$ per $50 \mathrm{~kg}$ of cement) was also used. The average compressive strength (from testing three $150 \times 150 \times 150 \mathrm{~mm}$ cubes at 28 -days age) for each mix is shown in Table 3.

\subsection{Testing Procedure}

Two concentrated vertical loads, $300 \mathrm{~mm}$ apart, were subjected to each beam. The sheer span and net span were $385 \mathrm{~mm}$ and $1070 \mathrm{~mm}$, respectively. While the ratio of span/depth ratio was 2.68 (satisfying $\mathrm{L} / \mathrm{h}<4$ as recommended by ACI code [1] for the requirements of deep beams). To avoid concrete crushing under the points loads, bearing plates above supports and under loads were used. The vertical load was subjected at $5 \mathrm{kN}$ increment per (second)?. At each increment, deflections at mid-span and the width of shear crack were recorded via a dial-gauge and zooming in tool (crackmeter), respectively. Fig. 2 depicts the testing setup.

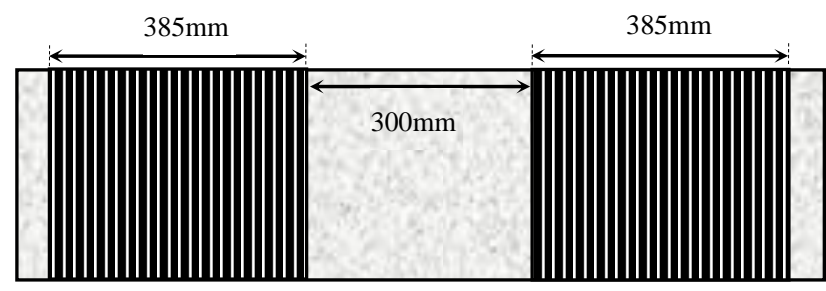

(a) Beams (DBFV\#1) and (DBFV\#2)

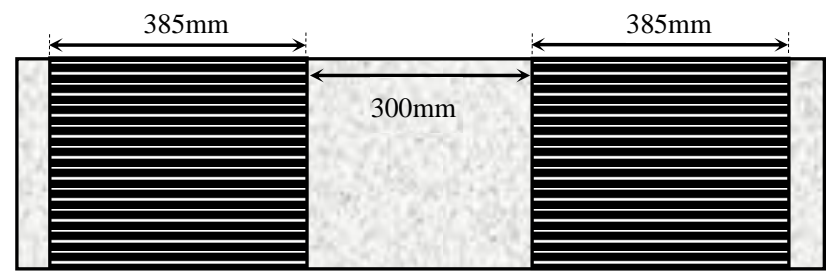

(b) Beams (DBFH\#1) and (DBFH\#2)

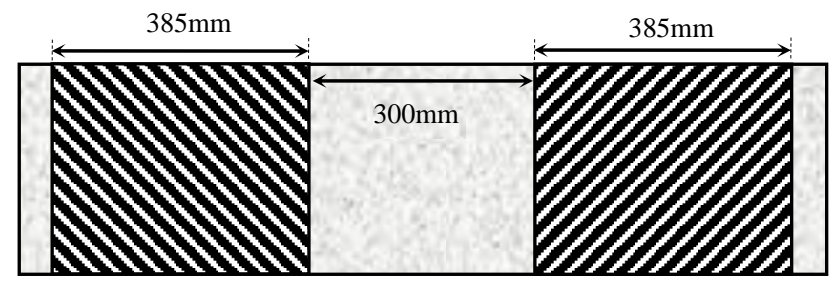

(c) Beams (DBFI\#1) and (DBFI\#2)

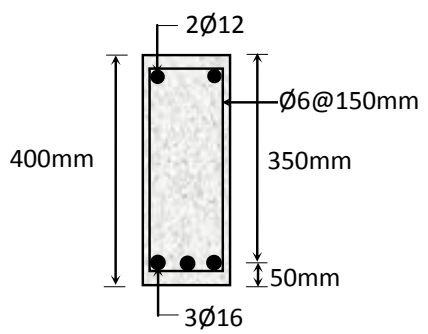

(d) Cross sectional details of all beams

Figure 1. Details of beams 


\section{Table 1 - Beams Details}

\begin{tabular}{|c|c|c|c|c|c|}
\hline $\begin{array}{c}\text { Beam } \\
\text { designation }\end{array}$ & $\begin{array}{c}\text { CFRP } \\
\text { orientation }\end{array}$ & $\begin{array}{c}\text { Width } \\
(\mathbf{m m})\end{array}$ & $\begin{array}{c}\text { Depth } \\
(\mathbf{m m})\end{array}$ & $\begin{array}{c}\text { Span } \\
(\mathbf{m m})\end{array}$ & $\begin{array}{c}\text { (a/d) } \\
\text { ratio }\end{array}$ \\
\hline DBC\#1 & - & 150 & 400 & 1070 & 1.1 \\
\hline DBC\#2 & - & 150 & 400 & 1070 & 1.1 \\
\hline DBFV\#1 & Vertical & 150 & 400 & 1070 & 1.1 \\
\hline DBFV\#2 & Vertical & 150 & 400 & 1070 & 1.1 \\
\hline DBFH\#1 & Horizontal & 150 & 400 & 1070 & 1.1 \\
\hline DBFH\#2 & Horizontal & 150 & 400 & 1070 & 1.1 \\
\hline DBFI\#1 & Inclined & 150 & 400 & 1070 & 1.1 \\
\hline DBFI\#2 & Inclined & 150 & 400 & 1070 & 1.1 \\
\hline
\end{tabular}

Table 2 - Materials properties

\begin{tabular}{|c|c|c|c|}
\hline Material & Type & $\begin{array}{c}\text { Ultimate } \\
\text { Strength } \\
(\mathbf{M P a})\end{array}$ & $\begin{array}{c}\text { Modulus of } \\
\text { Elasticity } \\
\text { (GPa) }\end{array}$ \\
\hline Steel bars (Ø16mm) & Mild steel & $560^{*}$ & $201^{*}$ \\
\hline Steel bars $(\varnothing 6 \mathrm{~mm})$ & Mild steel & $515^{*}$ & $198^{*}$ \\
\hline FRP strips & SikaHex230 & $3500^{* *}$ & $230^{* *}$ \\
\hline Epoxy resin & SikaDur330 & $30^{* *}$ & $3.8^{* *}$ \\
\hline
\end{tabular}

* From the tension test of three specimens.

** From the manufacturer.

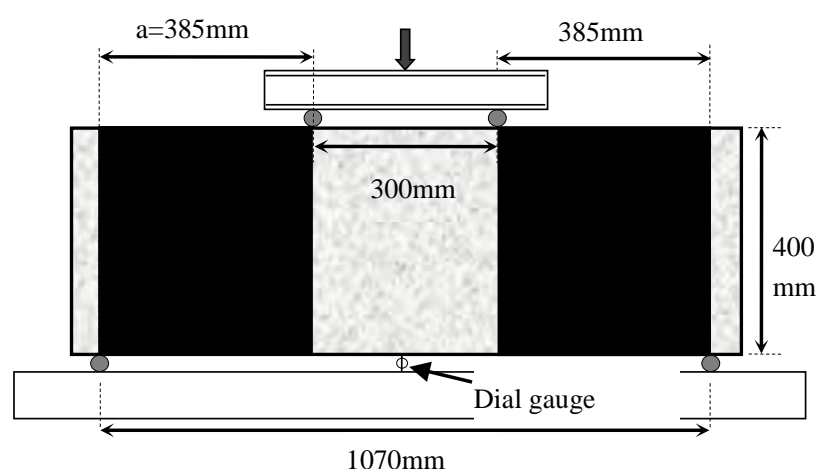

Figure 2. Testing Setup

\section{Results and Discussion}

Table 3 gives an outline of the experimental results. The cracking and ultimate loads with their corresponding deflections are shown in the former table.

\subsection{Modes of Failure}

All of the tested beams were failed in the same manner by a diagonal shear cracking resulting in rupture of FRP strips. Fig. 3 depicts strengthened specimens

\section{Table 3 - Experimental results}

\begin{tabular}{|c|c|c|c|c|c|}
\hline $\begin{array}{c}\text { Beam } \\
\text { designation }\end{array}$ & $\begin{array}{c}\text { Concrete } \\
\text { compressive } \\
\text { Strength } \\
\text { (MPa) }\end{array}$ & $\begin{array}{c}\text { Cracking } \\
\text { load } \\
\text { (kN) }\end{array}$ & $\begin{array}{c}\text { Deflection } \\
\text { at } \\
\text { cracking } \\
\text { load } \\
\text { (mm) }\end{array}$ & $\begin{array}{c}\text { Ultimate } \\
\text { load } \\
\text { (kN) }\end{array}$ & $\begin{array}{c}\text { Deflection } \\
\text { at } \\
\text { ultimate } \\
\text { load } \\
(\mathbf{m m})\end{array}$ \\
\hline DBC\#1 & 59.8 & 92 & 0.51 & 374 & 3.68 \\
\hline DBC\#2 & 59.8 & 94 & 0.49 & 382 & 3.72 \\
\hline DBFV\#1 & 61.2 & 101 & 0.58 & 557 & 5.03 \\
\hline DBFV\#2 & 61.2 & 99 & 0.57 & 561 & 5.05 \\
\hline DBFH\#1 & 60.8 & 108 & 0.54 & 452 & 3.93 \\
\hline DBFH\#2 & 60.8 & 107 & 0.54 & 450 & 4.07 \\
\hline DBFI\#1 & 59.3 & 97 & 0.53 & 524 & 4.96 \\
\hline DBFI\#2 & 59.3 & 93 & 0.55 & 518 & 4.87 \\
\hline
\end{tabular}

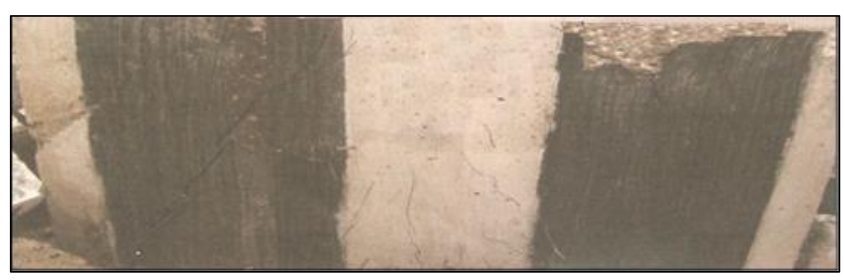

(a) Beam (DBFV\#1)

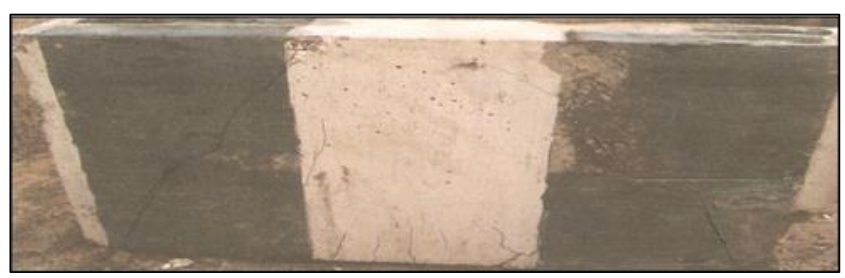

(b) Beam (DBFH\#1)

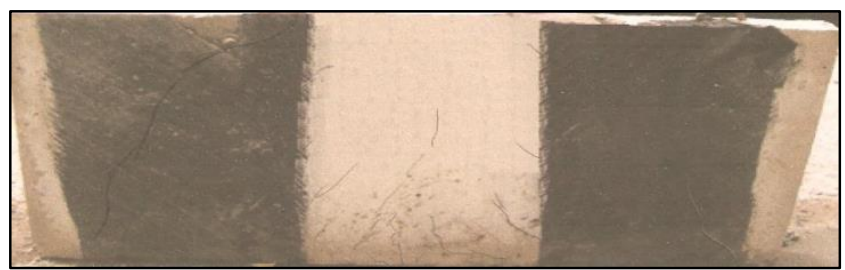

(c) Beam (DBFI\#1)

Figure 3. Strengthened beams after failure

after failure. In all of the tested beams, cracking was started by flexural cracks closely to midspan. No cracks were recorded up to approximately one fifth of the ultimate load. For the beams (DBC) and (DBFH), the first flexural crack appeared at $24 \%$ of ultimate load, while it cracked at $18 \%$ of the ultimate load for the beams (DBFV) and (DBFI). At approximately half of the ultimate load, an inclined diagonal crack began to appear at the left or right shear span region. As loading increased, additional inclined cracks appeared within the region between supports. Finally, failure occurred by concrete rupture or crushing at either the tip or along the diagonal crack. 


\subsection{Load Carrying Capacity}

Fig. 4 shows the ultimate load of all of the tested beams, while the percentage increase in the ultimate load of strengthened beams, with respect to the unstrengthened beam (average of each two identical beams), is shown in Fig. 5.

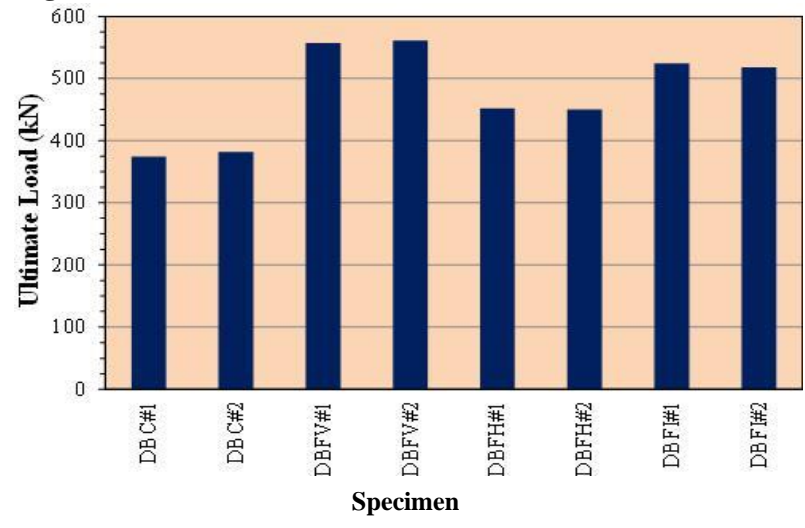

Figure 4. The ultimate load of all tested beams

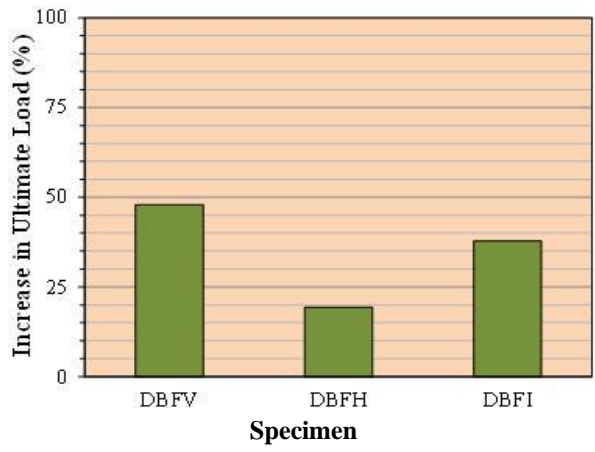

Figure 5. Percentage increase in ultimate loads

The two beams (DBC) were considered as control beams with no any FRP strengthening. They were failed at an average load of $378 \mathrm{kN}$. Beams (DBFV) were strengthened by FRP strips with a vertical orientation. Their failure was due to a diagonal crack at an average load of $559 \mathrm{kN}$ resulting in an increase in load carrying capacity of $48 \%$ compared with that of the beams (DBC). While the beams (DBFH), strengthened by FRP strips with a horizontal orientation, were failed by a diagonal crack at an average load of $451 \mathrm{kN}$ giving an increase in the beam capacity of $19 \%$ compared with that of the beams (DBC). Beams (DBFI) were strengthened by FRP strips with an inclined orientation and their failure was due to a diagonal crack at an average load of $521 \mathrm{kN}$ resulting in an increase in load carrying capacity of $38 \%$ compared with that of the beams (DBC). It is obvious that the beams (DBFV), which strengthened with FRP strips of inclined orientation, showed the greatest ultimate load. Thus the vertical orientation pattern of strengthening gives the highest capacity as compared with those of inclined and horizontal orientation patterns. On the other hand, the horizontal orientation pattern of strengthening gives the lowest load carrying capacity.

\subsection{Load-Deflection Behavior}

Fig. 6 exhibits the load-deflection relationships of all the tested beams. For comparison task, the load-deflection relationships of the beams DBC\#1, DBFV\#1, DBFH\#1 and DBFI\#1 are gathered in Fig. 7.

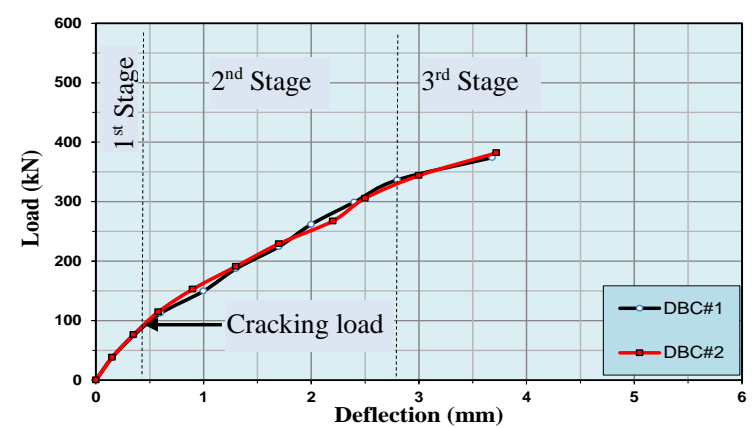

(a) Beams (DBC\#1) and (DBC\#2)

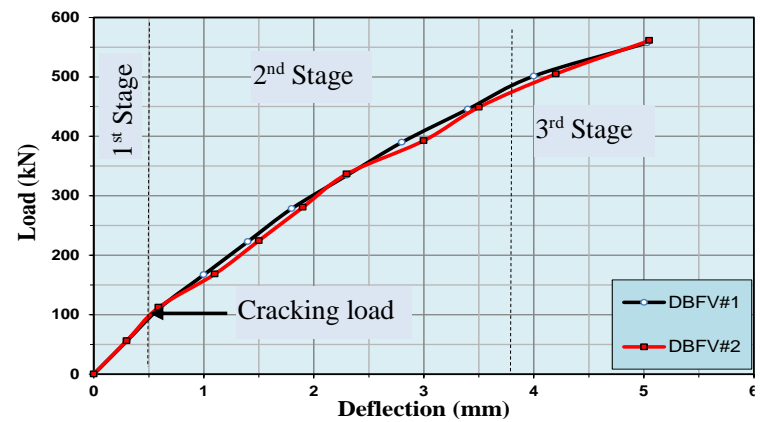

(b) Beams (DBFV\#1) and (DBFV\#2)

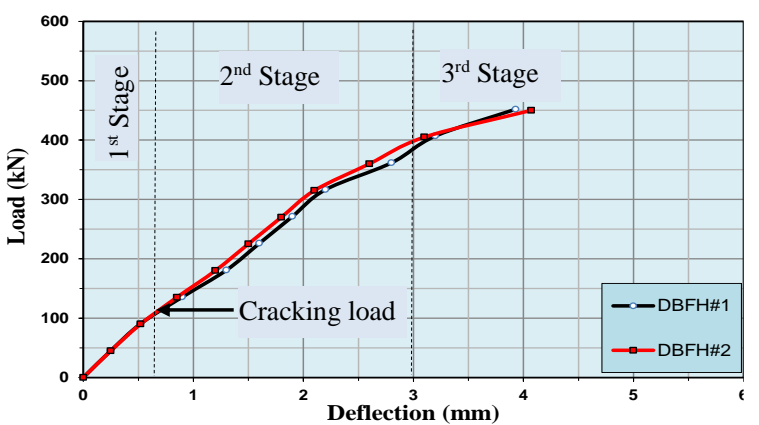

(c) Beams (DBFH\#1) and (DBFH\#2)

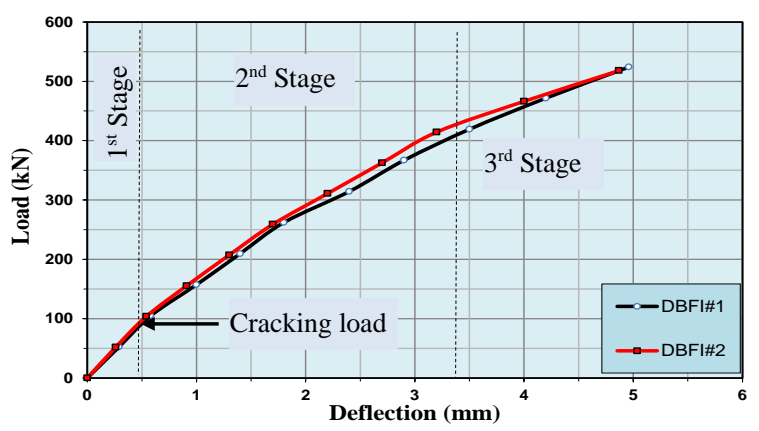

(d) Beams (DBFI\#1) and (DBFI\#2)

Figure 6. Load-deflection relationship of tested beams 


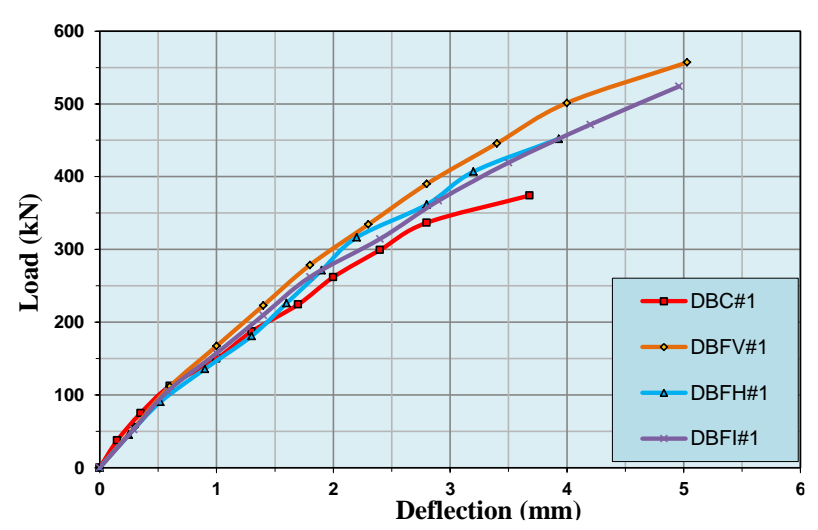

Figure 7. Load-deflection relationship of beams DBC\#1, DBFV\#1, DBFH\#1 and DBFI\#1

From the above curves, it can be demonstrated that the load-midspan deflection response can be divided into (3) stages. In the first stage, a linear relationship was noted in which the load and deflection are proportional. This stage continues to the cracking load. The first deviation to this linear relationship corresponds to this cracking load and the end of this stage represents the proportional limit. Within this stage, the materials, concrete and reinforcement, behave as elastic materials and the small cracks developed in the tension section of the beams are still stable. Beyond this, the propagation of cracks continues with an increase in their width as loading increases. In the second stage, a nonlinear relationship is observed. This stage begins from the proportional limit and ends near the ultimate load. At the third stage, where the subjected load closes to its ultimate value, the deflection increases at a greater rate compared with the rate of the applied load.

As can be seen from Fig. 7, decreasing in the slope of the second stage for unstrengthened control beams is greater than that of strengthening beams. Due to the presence of FRP strips, strengthened beams undergo large deflections at the ultimate condition as referenced to the unstrengthened beams. The average increases in deflection at ultimate load were 36,8 and $33 \%$ for vertical, horizontal and inclined strengthening orientation, respectively. Thus, strengthening with FRP strips of vertical fabric orientation is more efficient than strengthening with horizontal or inclined orientation since the vertical orientation gives the highest ultimate load and largest deflections at ultimate load. On the other hand, it has seemed that the horizontal orientation is considered inadequate for the strengthening purposes since it gives ultimate load and corresponding deflection not much greater than those of the unstrengthened control beams.

\subsection{Shear Crack Pattern}

The load causes the appearance of the diagonal crack is called the shear cracking load. This crack suddenly appears at the mid of shear span. As loading increased, the diagonal crack extends towards the loading and support points. Its maximum width usually occurred at the beam's middepth.

Fig. 8 gives the width of shear crack against the applied load for the beams DBC\#1, DBFV\#1, DBFH\#1 and DBFI\#1. The cracks width was recorded up to approximately $95 \%$ of the ultimate load since it cannot be recorded at ultimate load. From this figure, the maximum crack widths were 4.1, 1.2, 3.6 and $1.4 \mathrm{~mm}$ for beams DBC\#1, DBFV\#1, DBFH\#1 and DBFI\#1, respectively. It is obvious that the unstrengthened beam exhibits relatively large crack width at failure and the FRP strengthening minimizes the width of cracks. For the beam (DBFV\#1), the percentage decrease in maximum crack width was about $70 \%$ of that for the beam (DBC\#1). Strengthening with vertical or inclined FRP strips is very adequate in minimizing the crack width as compared with horizontal FRP strips.

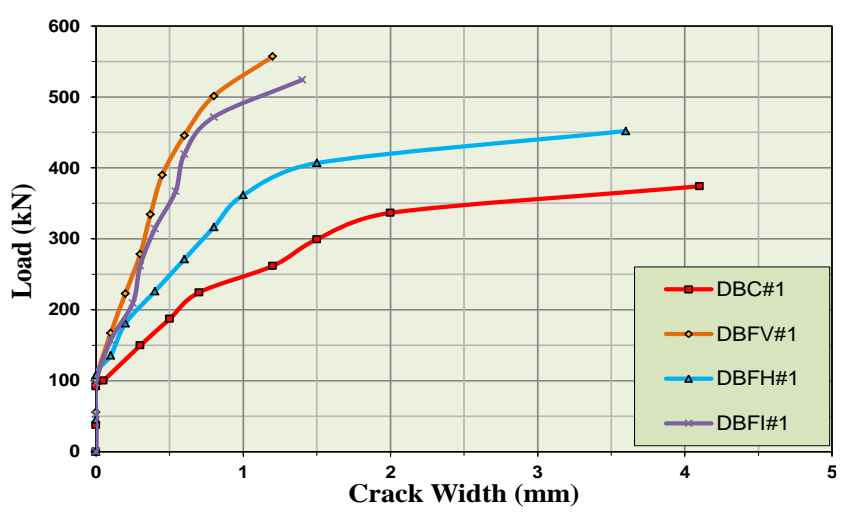

Figure 8. Load-crack width relationship

\section{Conclusions}

The following points can be presented as a conclusion for this study:

- All of the strengthened beams were failed in the same manner by a diagonal shear crack resulting in rupture of FRP strips.

- A gaining in load carrying capacity of 48,19 and $38 \%$ (compared with the unstrengthened beam) was observed for beams strengthened with vertical, horizontal and inclined FRP strips, respectively.

- $\quad$ For strengthened beams, the load-midspan deflection response was much stiff than that of the unstrengthened beams.

- $\quad$ Strengthening with FRP strips minimizes the width of cracks. For the vertical strengthening, the percentage decrease in the maximum crack width was about $70 \%$ of the maximum crack width of the unstrengthened beam.

- $\quad$ Strengthening with FRP strips of vertical fabric orientation is more efficient than strengthening with horizontal or inclined orientation since the vertical orientation gives the highest load carrying capacity, largest deflections at ultimate load and smallest crack width.

- It seemed that the horizontal orientation was inadequate for the strengthening purposes since it gives ultimate load and corresponding deflection not much greater than those of the unstrengthened control beams.

\section{REFERENCES}

[1] ACI Committee 440, 2014, "Guide for the design and construction of externally bonded FRP systems for strengthening of concrete structures," American Concrete Institute, Michigan, USA.

[2] K.H. Yang, A.F. Ashour, and J.K. Song, 2007, "Shear Capacity of Reinforced Concrete Beams Using Neural Network," International Journal of Concrete Structures and Materials, 1(1):63-73.

[3] N.F. Grace, A.K. Soliman, G. Abdel-Sayed, and K.R. Saleh, 1998, "Behavior and Ductility of Simple and Continuous FRP Reinforced Beams," ASCE Journal of Composites for Construction, 2(4):186 - 194.

[4] M.R. Islam, M.A. Mansur, and M. Maalej, 2005, "Shear strengthening of RC deep beams using externally bonded FRP systems", Cement and 
Concrete Composites, 27(3):413-42.

[5] B.I. AL-Shraify, 2009, "Behavior of Reinforced Concrete deep beams Strengthened with Carbon Fiber Reinforced Polymer Strips", Ph.D thesis, University of Baghdad.

[6] H.K. Lee, S.H. Cheong, S.K. Ha, and C.G. Lee, 2011, "Behavior and performance of RC T-section deep beams externally strengthened in shear with CFRP sheets", Composite Structures, 93(2):911-922.

[7] R.A. Abbas and M.D. Abdulah, 2013, "Behavior of reinforced concrete deep beams strengthened with CFRP sheets", Elixir Cement and Concrete Composites, 62(2013): 17696-17700.

[8] P.C. Chavan, C.P. Pise, Y.P. Pawar, and S.S. Kadam, 2017, "Strengthening of Reinforced Concrete Deep Beam Using FRP Wrapping”, Inter. J. of ENG. SCI. \& Research Technology, 6(11):347-358.

[9] N.A. Alwash, bylon, G.M. Habeeb, and F.H. Al-Mamoori, 2017, "Flexural Behavior of Light Weight Concrete Slab Panels Reinforced with CFRP Bars", Al-Qadisiyah Journal for Engineering Sciences, 10(4):368-383.

[10] R.F. Makki, A.T. Jassem, and H. A. Jassem, 2018, "Non-Linear Analysis of Reactive Powder Concrete (RPC) Deep Beams with Openings Strengthened by CFRP”, Al-Qadisiyah Journal for Engineering Sciences, 11(2):176-196. 